\title{
TABULEIRO DA GEOGRAFIA: PROTÓTIPO DE JOGO PARA CRIANÇAS DEFICIENTES VISUAIS
}

\section{GEOGRAPHY BOARD: PLAY PROTOCOL FOR VISUAL DEFICIENT CHILDREN}

\author{
HEIDRICH, Regina De Oliveira; Doutora em Design; Universidade Feevale \\ RHeidrich@feevale.br \\ RADAI, Ketlin Da Silva; Bacharela em Design; Universidade Feevale \\ Ketlinrs@gmail.com
}

\begin{abstract}
Resumo
O design universal é considerado um movimento mundial, baseado no conceito de que todos os produtos, ambientes e etc., sejam bem concebidos, pensando-se atender às necessidades da grande maioria dos usuários (NSCU, 1998). Perante a esse conceito, este projeto teve como objetivo desenvolver um material didático e lúdico de cunho inclusivo de uso comum na educação infantil para crianças cegas e videntes, tendo como premissa desenvolver um projeto de Design Universal, visando uma melhor aprendizagem no conteúdo de Geografia. Para a realização do projeto, foi utilizada a metodologia de Inclusive Design Toolkit (Conjunto de Ferramentas de Design Inclusivo), desenvolvida pela Engineering Design Centre (2017) da Universidade de Cambridge do Reino Unido. Essa metodologia e suas ferramentas possibilitaram uma total imersão com o público-alvo, na qual foi permitido idealizar e aplicar um protótipo de jogo, onde os alunos pudessem, através de um quebra-cabeça tátil brincar aprendendo.
\end{abstract}

Palavras Chave: Deficientes visuais, Design universal, Geografia.

\begin{abstract}
Universal design is considered a worldwide movement, based on the concept that all products and etc., are well-designed, thinking of going towards the needs of the vast majority of users (NSCU, 1998). Bearing this concept in mind, this project aimed to develop a didactic and playful material of common use in children's education for blind and sighted children, with the premise of developing a Universal Design project, aiming a better learning in the content of Geography. To implement the project, the Inclusive Design Toolkit methodology, developed by the Engineering Design Center (2017) at the University of Cambridge in the United Kingdom, was used. This methodology and its tools allowed a total immersion with the target audience, in which it was possible to idealize and apply a prototype game, where students could, through a tactile puzzle, play around and learn. Keywords: Visually impaired, Universal design, Geography.
\end{abstract}




\section{Introdução}

A educação de alunos deficientes visuais têm vivido ainda a concepção tradicional da educação geral em nosso país. E não poderia ser diferente, pois o aluno deficiente visual está integrado no sistema regular de ensino, com a mesma proposta educacional e os mesmos programas e conteúdos desenvolvidos pela escola. Segundo o INEP/MEC (2013) aproximadamente 70 mil crianças cegas ou com diferentes graus de cegueira em todo o Brasil frequentam a escola regular, porém, é notório que diversas escolas não possuem um assessoramento para com os professores e funcionários, tornando o aluno deficiente visual propenso a tomar decisões com bastante vulnerabilidade. A criança deficiente visual necessita de atendimento e material adaptado, isto é, necessita de professores especializados, adaptações curriculares e materiais adicionais de ensino, para auxiliá-la a atingir um nível de desenvolvimento proporcional às suas capacidades.

O design universal no auxílio a crianças deficientes visuais nos ambientes escolares vem crescendo diariamente, fazendo com que os professores busquem novas metodologias de ensino para diversos conteúdos como matemática, história e português. Já na matéria de geografia, por englobar diversos assuntos como relevos, políticas e fusos horários existe uma dificuldade em trazer novos materiais. Problema esse que afeta os alunos com deficiência visual, pois os livros didáticos normalmente não trazem a leitura em Braille e muito menos fonte ampliada para crianças com baixa visão (DIAS, 2007). Dessa forma, a carência de materiais didáticos táteis e de uso coletivo por todos os alunos é uma questão de extrema importância.

Sendo assim, o objetivo do presente artigo consiste em desenvolver, através do design, um material didático para crianças deficientes visuais que busque aprimorar o conhecimento das mesmas na disciplina de Geografia no sexto ano.

\section{Desenvolvimento}

\subsection{Acessibilidade}

Muito se discute sobre a acessibilidade, sendo a mesma um objeto de extrema importância para a inclusão social. Ao observarmos a quantidade de grupos de pessoas que, por várias razões, carecem de condições adequadas para ir e vir, manejar, utilizar e comunicar ou compreender informações. É preciso considerar que, além das pessoas com deficiência, que são 24,6 milhões no Brasil, as mulheres gestantes, pessoas obesas, pessoas com lesões transitórias são exemplos de pessoas que também necessitam de boas condições de acessibilidade em seu dia-a-dia (PINHEIRO, 2005).

Vital e Resende (2008), a respeito da Convenção sobre os Direitos das Pessoas com Deficiência, afirmam sobre acessibilidade:

A Convenção se refere à acessibilidade como ferramenta para que as pessoas com deficiência atinjam sua autonomia em todos os aspectos da vida, o que demonstra uma visão atualizada das especificidades destas pessoas, que buscam participar dos meios mais usuais que a sociedade em geral utiliza para funcionar plenamente nos dias de hoje, não se reduzindo apenas à acessibilidade ao meio físico [...] A acessibilidade ao meio físico promove a inclusão, a equiparação de oportunidades e o exercício da cidadania para todas as pessoas. Ações que garantam a acessibilidade para pessoas com restrição de mobilidade aos sistemas de transportes, equipamentos urbanos e a circulação em áreas 
públicas são, nada mais, que o respeito de seus direitos fundamentais como indivíduos. (VITAL; RESENDE, 2008, p. 45).

Com a inclusão social, a acessibilidade é entendida, atualmente, não apenas pela adaptação arquitetônica, mas também pela proporcionalidade da comunicação e, consequentemente, eliminação de barreiras de atitudes pedagógicas, entre tantas outras. Percebe-se que as limitações de uma pessoa com deficiência tendem a tornar-se uma barreira ao aprendizado e, consecutivamente, às atividades exercidas no dia a dia. Além disso, há o preconceito que a pessoa com deficiência está sujeita por não conseguir realizar as tarefas (VITAL; RESENDE, 2008).

Dessa forma, afim de permitir a eficácia da acessibilidade da pessoa deficiente visual, o conhecimento do espaço e da autonomia de decisão possui extrema importância. Essas ações incluem o design de mapas táteis e modelos, descrições orais e treinamento dos usuários (BINS ELY,2004).

\subsection{Design Universal}

O conceito de design universal, criado por uma comissão em Washington, EUA, foi primeiramente chamado de "Desenho Livre de Barreiras", por voltar-se à eliminação de barreiras nas construções arquitetônicas dos edifícios, equipamentos e áreas urbanas (SÃO PAULO, 2005). O design universal tem como sua interpretação a construção de ambiente, espaços e tecnologias de uma maneira que sua diversidade seja compreendida em relação às características físicas, habilidades e experiência pessoal em relação ao ambiente (PINTO, 2009).

De acordo com Dischinger \& Mattos (2002), o Design Universal não é uma tendência de projeto, mas uma postura fundamental para promover a acessibilidade de todos os usuários, refletindo, dessa forma, nos métodos de desenvolvimento de projeto e nos próprios resultados projetuais. Sendo assim, projetar produtos e meios físicos acessíveis é uma iniciativa que requer atenções específicas à compreensão da diversidade humana.

Os princípios do Design Universal foram desenvolvidos por profissionais de diversas áreas como arquitetura, design, engenharia e por pesquisas na área de design ambiental coordenadas pelo Centro de Design Universal da Universidade Estadual da Carolina do Norte (NCSU, 1998). Dessa forma, foram criados os sete princípios do design universal: uso equitativo, flexibilidade de uso, simples uso intuitivo, informações perceptíveis, tolerância ao erro, baixo desgaste físico, tamanho e espaço para uso e alcance.

Levando em consideração os fatores como a segurança, funcionalidade, satisfação do usuário como elementos fundamentais para a criação de um produto, princípios do design universal, faz parte do processo de desenvolvimento como um todo buscar atender as necessidades da maioria dos usuários. Os produtos e ambientes criados com Design Universal não parecem ser feitos especialmente para pessoas com deficiência, eles equiparam o uso a todo tipo de usuário, dessa forma, o Design Universal pode ser chamado "desenho para todos" (CONDE, 1994).

\subsection{Tecnologia Assistiva}

De acordo com o Comitê de Ajudas Técnicas, o conceito de tecnologia assistiva é uma área do conhecimento, de característica interdisciplinar, que engloba produtos, recursos, metodologias, estratégias, práticas e serviços que objetivam promover a funcionalidade, 
relacionada à atividade e participação, de pessoas com deficiência, incapacidades ou mobilidade reduzida, visando sua autonomia, independência, qualidade de vida e inclusão social (BRASIL, 2009, pág. 09).

As bases para formulação conceitual de Tecnologia Assistiva adotadas pelo Comitê de Ajudas Técnicas são: área do conhecimento, interdisciplinaridade, objetivos, composição, considerar os princípios do Desenho Universal e da Tecnologia Social. A utilização e evolução de produtos de tecnologia assistiva surgem como ferramentas na concretização desses direitos. Nos últimos anos, vários produtos e serviços foram criados com a função de reduzir as barreiras diárias das pessoas com deficiência, nos diferentes planos de suas vidas (SPERB, 2015).

\subsection{Pessoas com deficiência}

Publicada em 1980, a Classificação Internacional das Deficiências, Incapacidades e Desvantagens é conhecida internacionalmente por ICIDH, tem sido utilizada, como elemento regulador, para diversos fins, quer como ferramenta estatística e de investigação, quer pela segurança social, por seguradoras, ou outras entidades que necessitem de classificar questões relacionadas com a saúde (FALCATO, et. al., 2006). Conforme o Estatuto da Pessoa com Deficiência, criado em 2015, o Artigo 2 nos traz a seguinte definição:

\section{Considera-se pessoa com deficiência aquela que tem impedimento de longo prazo de natureza física, mental, intelectual ou sensorial, o qual, em interação com uma ou mais barreiras, pode obstruir sua participação plena e efetiva na sociedade em igualdade de condições com as demais pessoas (BRASIL, 2015 pág. 09).}

$\mathrm{Na}$ Classificação Internacional das Deficiências, Incapacidades e Desvantagens (ICIDH), as deficiências dividem-se em categorias, tais como psíquicas, sensoriais, físicas, mistas e nenhuma deficiência em especial. (FALCATO, et. al., 2006).

No Brasil, segundo o Instituto Brasileiro de Geografia e Estatística (IBGE), 45.606 .048 brasileiros, $23,9 \%$ da população total, têm algum tipo de deficiência - visual, auditiva, motora e mental ou intelectual. A prevalência da deficiência variou de acordo com a natureza delas. A deficiência visual apresentou a maior ocorrência, afetando $18,6 \%$ da população brasileira. Em segundo lugar, está a deficiência motora, ocorrendo em 7\% da população, seguidas da deficiência auditiva, em 5,10\% e da deficiência mental ou intelectual, em 1,40\%.

O Censo 2010 mostra ainda que existe uma diferença significativa no nível de escolaridade entre pessoas com deficiência e a população geral - 61,1\% da população com 15 anos ou mais com deficiência não têm instrução ou têm apenas o fundamental incompleto. Esse porcentual cai para $38,2 \%$ quando são pessoas sem deficiência.

\subsection{Pessoas com deficiência visual}

Segundo Vital e Resende (2008), a autonomia está relacionada ao domínio do ambiente, a executar atividades do cotidiano, ir e vir e utilizar equipamentos sem o auxílio de terceiros. É, portanto, diferente de independência, que é a capacidade de tomar as próprias decisões. Autonomia compreende a capacidade de realizar atividades sem a ajuda de terceiros, com dignidade.

A visão reina soberana na hierarquia dos sentidos e ocupa uma posição notável no que refere à integração de formas, contornos, tamanhos, cores e imagens que estruturam a composição de um ambiente. É o elo com os outros sentidos, permite associar som e imagem, 
imitar um gesto ou comportamento e exercer uma atividade exploratória a um espaço delimitado (DIAS, et. al., 2007). Segundo o Conselho Brasileiro de Oftalmologia (CBO), a cegueira é uma alteração grave ou total de uma ou mais das funções indispensáveis da visão que afeta a capacidade de perceber um campo mais ou menos abrangente. Pode ocorrer desde o nascimento, ou posteriormente, em decorrência de causas orgânicas ou acidentais.

As informações tátil, auditiva, sinestésica e olfativa são mais desenvolvidas pelas pessoas cegas, porque elas recorrem a esses sentidos com mais frequência para decodificar e guardar na memória as informações. Sem a visão, os outros sentidos passam a receber a informação de forma intermitente, fugidia e fragmentária (FALCATO, et. al., 2006).

O desenvolvimento fino da audição, do tato, do olfato e do paladar é resultado do uso contínuo desses sentidos pela necessidade muito frequente. Portanto, não é um fenômeno extraordinário ou um efeito compensatório. Os sentidos remanescentes funcionam de forma complementar e não isolada. A audição desempenha um papel relevante na seleção e codificação dos sons que são significativos e úteis. A habilidade de atribuir significado a um som sem perceber visualmente a sua origem é difícil e complexa. A experiência tátil não se limita ao uso das mãos. $O$ olfato e o paladar funcionam conjuntamente e são auxiliadores indispensáveis (FALCATO, et. al., 2006).

\subsection{Inclusão escolar de crianças deficientes visuais}

A inclusão escolar teve seu início a partir da necessidade de atender alunos deficientes no que repercute a obtenção de conhecimento, pois os mesmos nem sempre tiveram acesso a ela na forma escolarizada. Segundo o MEC (2000), a atividade predominante da criança entre os seis e os dez anos de idade, em média, consiste em estudar. A escola passa a ser um local de aprendizagem e de socialização, determinando a rotina e o ritmo de sua vida. Nessa fase, a criança aprende a ler e a escrever, abrindo-se novos horizontes.

A criança cega muitas vezes chega à escola sem um "passado" de experiências, não apresenta os seus conceitos básicos como esquema corporal, lateralidade, orientação espacial e temporal, que são quase inexistentes. Ademais, sua mobilidade é difícil, o que poderá levar à baixa autoestima e dificultará o seu adequamento à escola, isto é, a sua inclusão de fato (DIAS, 2007). Dessa forma, muitas instituições vêm transferindo suas frustrações, ora pelos educadores e administradores despreparados profissionalmente, ou pessoalmente para essas mudanças no sistema educacional, ora substituindo a responsabilidade às características especiais do aluno com deficiência (SALVADOR, 2003).

Devido ao crescimento de alunos com deficiência nas escolas regulares, muitos professores não se sentem preparados para atender as particularidades que esses alunos apresentam. Para muitos, existem a ausência de informação sobre as deficiências e síndromes. Falta também capacitação profissional, o que pode acarretar bloqueios para o desenvolvimento da qualidade na escola que se diz para todos (SILVA, et. al., 2016).

Um dos principais problemas do deficiente visual é a dificuldade de contato com o ambiente físico. Além disso, há a carência de material adequado pode conduzir a aprendizagem da criança deficiente visual a um mero verbalismo, desvinculado da realidade. A formação de conceitos depende do íntimo contato da criança com as coisas do mundo. Tal como a criança de visão normal, a deficiente visual necessita de motivação para a aprendizagem. 0 manuseio de 
diferentes materiais possibilita o treinamento da percepção tátil, facilitando a discriminação de detalhes e suscitando a realização de movimentos delicados com os dedos.

Conforme os autores Manzini e Deliberato (2007), o recurso pedagógico é construído com o objetivo de ser algo específico para o aluno, que ele possa manipular, e que tenha alguma finalidade pedagógica. Então, avaliar os recursos e tecnologias que podem ser utilizados pelos alunos com deficiência visual em sua forma original é um ponto de partida.

\subsection{Materiais didáticos para alunos deficientes visuais}

Alunos que possuem deficiência visual não devem ser educados separadamente, mas, sim, frequentar escolas regulares tendo suas necessidades supridas por uma sala de recursos. Essas salas de recursos funcionam proporcionando suporte ao aluno e ao professor de uma sala comum, carecendo servir como um complemento às aulas trazidas à turma, eliminando as dificuldades e eventuais dúvidas naturais da deficiência visual do aluno (SANTOS, 2015).

As salas de recursos multifuncionais são ambientes educacionais dotados de equipamentos específicos e recursos de acessibilidade, mobiliários e materiais didáticos e pedagógicos para a oferta do atendimento educacional especializado. Os objetivos dessas salas são prover condições de acesso, participação e aprendizagem no ensino regular desses alunos, impulsionar o desenvolvimento de recursos didáticos e pedagógicos que eliminem as barreiras no processo de ensino e aprendizagem e se certificar das condições para a continuidade de estudos nos demais níveis de ensino (BRASIL, 2008).

Para favorecer a comunicação e a adaptação entre todos os alunos, é indispensável que os recursos didáticos possuam estímulos visuais e táteis que atendam às diferentes condições visuais. Dessa forma, o material deve apresentar cores contrastantes, texturas e tamanhos adequados para que se torne útil e significativo em todas as disciplinas (DIAS, 2007).

Os livros didáticos são ilustrados com desenhos, gráficos, cores, diagramas, fotos e outros recursos que, para o deficiente visual, tornam-se inacessíveis para seu aprendizado. A transcrição de um texto ou de um livro para o sistema Braille tem características específicas em relação ao tamanho, à paginação, à representação gráfica, aos mapas e às ilustrações, carecendo de ser fiel ao conteúdo e respeitar normas e critérios estabelecidos pela Comissão Brasileira do Braille (COSTA, 2009).

O sistema de escrita em relevo, conhecido pelo nome de "Braille" é constituído por 63 sinais formados por pontos a partir do conjunto matricial (123456), este conjunto de seis pontos chama-se sinal fundamental. O espaço por ele ocupado, ou por qualquer outro sinal, denomina-se cela Braille e, quando vazio, é também considerado por alguns especialistas como um sinal, passando assim o Sistema a ser composto com 64 sinais (BRASIL, 2006).

Na matéria de Matemática, um dos principais materiais utilizados na educação de crianças com deficiência visual é o Soroban. Esse material é um ábaco, adaptado para os cegos, com a finalidade de realização de cálculos das operações fundamentais, potenciação e radiciação, com grande eficiência e rapidez (REINEHER, 2008).

Segundo Isotani, et. al. (2008) "a inclusão das ferramentas da Web traz diversos benefícios para o ensino, principalmente por permitir novas práticas pedagógicas e formas de aprendizagem mais ativas e interativas". Além de vantagens em todos os níveis de ensino, a internet também pode ser utilizada na educação de diversas formas. Após a inclusão da internet, essas 
possibilidades se ampliaram mais, pois assim, os alunos podem ser ao mesmo tempo consumidores e produtores da informação, bem como os professores podem desenvolver estratégias que estimulem as múltiplas formas de aprendizagem (visual, auditiva, sinestésica).

Porém, diversas coisas que são vistas pelos olhos não estão ao alcance das mãos, devido ao tamanho original dos objetos, à distância, à localização e à impossibilidade de tocar, o que impossibilita ao aluno deficiente visual um ensino mais eficaz na matéria de geografia. Sendo assim, a utilização de maquetes e de modelos é uma boa maneira de trabalhar as noções e os conceitos relacionados aos acidentes geográficos, ao sistema planetário e aos fenômenos da natureza (DIAS, 2007).

\title{
2.8 A matéria de geografia
}

Ensinar Geografia deve ter muito mais significado do que simplesmente repetir os conteúdos de livros didáticos e fazer com que os alunos decorem nomes de lugares, de rios, de acidentes geográficos e conceitos utilizados na disciplina. $O$ dia-a-dia do professor em sala de aula é fundamental para possibilitar o entendimento crítico da Geografia para o aluno deficiente visual. Ao planejar suas aulas e preparar recursos didáticos, o professor precisa considerar as especificidades existentes em cada turma (SHAFEER, et. al., 2003).

\begin{abstract}
Limitados à leitura de textos e às exposições dos professores, os alunos encontram dificuldade para interagir com as diferentes linguagens e com os recursos próprios da Geografia [...]. Quando, na escola, vigoram estratégias de ensino centradas na voz do professor e na passividade do aluno, e o livro didático ainda comanda a cena em sala de aula, outros recursos de excepcional relevância [...] têm seu uso relegado. É compreensível que, neste caso, com alunos assim desatendidos, o conhecimento geográfico não seja construído e a memorização seja a forma habitual utilizada para mascarar o entendimento (SCHÄFFER, et. al., 2003, p.16).
\end{abstract}

Conforme Brumini (2016), em uma paisagem natural, o conjunto de forma da superfície terrestre constitui o relevo, importante elemento para a diversidade das paisagens e para a ocupação humana, que é composta de trechos, mais ou menos altos, inclinados, planos ou arredondados, que facilitam ou não a ocupação e o desenvolvimento de atividades humanas. Conforme a Figura 1, as principais formas de relevo são: montanhas, planaltos, depressões e planícies.

Figura 1 - Principais Tipos de Relevos
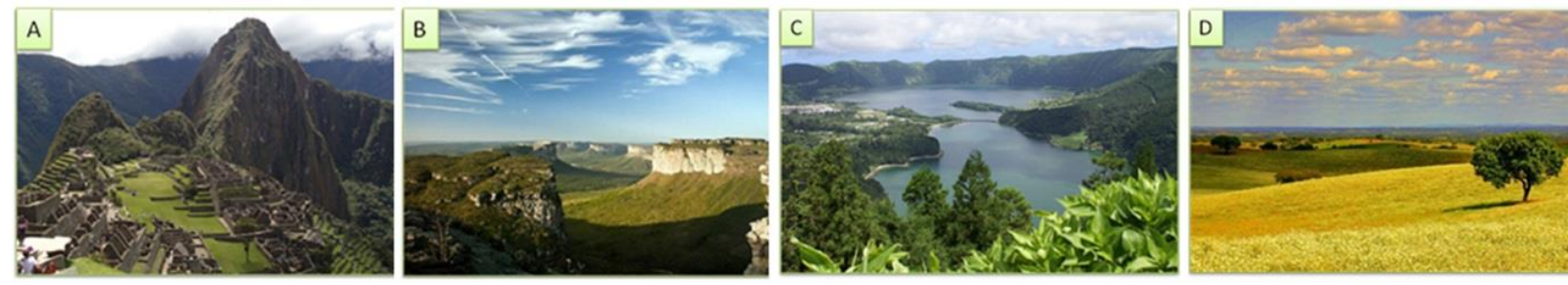

Fonte: Elaborada pela autora, 2017.

Montanhas: como mostra a Figura $1(\mathrm{~A})$, são terrenos de elevada altitude, superiores às das regiões vizinhas, geralmente onduladas. Alguns trechos das regiões montanhosas têm ocupação humana, como a região da Bolívia e Argentina. A ocupação nesse tipo de relevo é dificultada pelas altitudes elevadas e pelas formas íngremes.

Planaltos: conforme Figura 1 (B), são superfícies planas com bordas com um desnível 
acentuado no relevo devido ao processo de erosão e apresentam mais de 600 metros de altitude. Os morros são planaltos com topos arredondados e amplitude de relevo de 100 a 200 metros. Já as serras são formadas por cadeias de elevações pontiagudas, com amplitudes superiores a 200 metros (BRUMINI, 2016).

Depressões: segundo a Figura 1 (C), são divididas em duas categorias: depressões relativas, que são as áreas localizadas acima do nível do mar; e depressões absolutas, que são de áreas continentais abaixo do nível do mar (BRUMINI, 2016).

Planícies: segundo a Figura 3 (D), são formas baixas e planas que podem estar localizadas nas margens de rios, próximas aos oceanos ou no interior de planaltos e montanhas. Nessas áreas, predominam os processos de sedimentação, ou seja, o acúmulo de materiais trazidos de áreas mais altas (BRUMINI, 2016).

Segundo LIRA, et. al. (2010), para um melhor conhecimento e para o processo de ensinoaprendizagem dos alunos com deficiência visual é de extrema importância o uso de objetos tridimensionais, além de construção de maquetes com aproveitamento de sucatas, grãos de tamanhos e textura variados, tecidos e tintas em alto relevo. Tudo contribui para um melhor aprendizado.

\subsection{Design de superfície}

A superfície sempre serviu de suporte para expressar as necessidades do homem. Essa relação originou-se nos tempos primitivos, com os grafismos nas paredes das cavernas na préhistória. Ao longo do tempo, aumentou o interesse do homem em expressar-se graficamente, seu gosto pela decoração de superfície e a linguagem visual aplicada na tecelagem, na cerâmica e na estamparia carregaram o embrião do que hoje chamamos de Design de Superfície (RÜTHSCHILLING, 2008).

Em 2008, a definição do que é design de superfície sofreu uma modificação importante, complementando o conceito de simbólico, indispensável para afastar o design de superfície da ideia de apenas uma interferência secundária em um revestimento (FETTERMANN, 2016).

\footnotetext{
Design de Superfície é uma atividade criativa e técnica que se ocupa com a criação e desenvolvimento de qualidades estéticas, funcionais e estruturais, projetadas especificamente para constituição e/ou tratamentos de superfícies, adequadas ao contexto sociocultural e às diferentes necessidades e processos produtivos (RÜTHSCHILLING, 2008, p.23).
}

Com o grande crescimento no campo da tecnologia, a possibilidade da manifestação do design de superfície envolvendo interatividade por meio de computadores, sensores, elementos reativos que respondem ao movimento, sons, calor ou outras maneiras de estímulos, superou expectativas, de modo que o design não tenha apenas uma forma ou função (BARACHINI, 2002).

A superfície, ao funcionar como interface, acaba sendo a primeira instância de mediação física e cognitiva das interações entre o sujeito e o objeto. A compreensão da superfície como espaço sensorial já foi apontada por Barachini (2002, p. 3), quando esse afirmou que: "[...] as superfícies, como área de experimentação, criam condições múltiplas, podendo estabelecer outras inter-relações sensoriais, e, portanto, corporais ao objeto de design".

\section{Metodologia}


A metodologia desta pesquisa é de natureza teórico-aplicada, ou seja, que é motivada ao desenvolvimento de conhecimento para aplicação em seus resultados e soluciona problemas específicos. A forma de abordagem deste estudo é a qualitativa, que é uma seleção realizada do princípio da coleta de dados, fragmentando e extraindo o que é necessário e sempre analisando o valor de cada informação.

A pesquisa tem como objetivo a origem exploratória, proporcionando assim maior familiaridade com o problema e permitindo a construção de hipóteses. A pesquisa é do gênero bibliográfico, pois engloba pesquisa a partir de material publicado em livros, artigos, teses e materiais disponíveis na internet, cujo enfoque seja o aprendizado do conteúdo de Geografia para crianças do sexto ano com deficiência visual.

No desenvolvimento deste projeto, foi adotada a metodologia projetual chamada Inclusive Design Toolkit (Conjunto de Ferramentas de Design Inclusivo) elaborada por um grupo de pesquisadores na equipe de design inclusiva do Centro de Design de Engenharia da Universidade de Cambridge. A diversidade de usuários abrange uma variedade nas capacidades, necessidades e aspirações. As questões fundamentais de design são resolvidas através de sucessivos ciclos de exploração de necessidades, criando conceitos e avaliando opções, orientadas pelo gerenciamento de projetos.

Figura 2 - Principais etapas da metodologia projetual

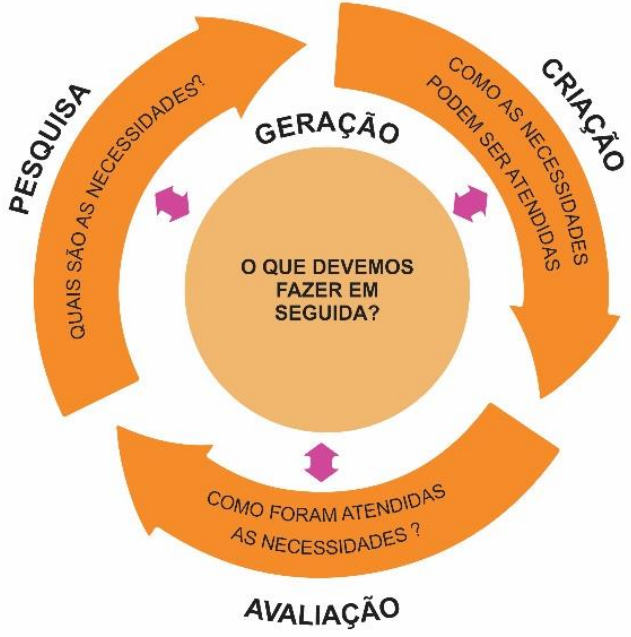

Fonte: Elaborada pela autora, 2017.

\section{Pesquisa}

Após a organização de todos os componentes da metodologia projetual e concluindo a primeira fase da geração, onde se obteve alguns refinamentos conceituais, iniciou-se a fase da pesquisa com os usuários, onde o principal objetivo é mostrar todos os usuários que contribuirão para o sucesso do produto. Isso ajudará mais tarde a capturar todas as necessidades que o produto deve cumprir.

\subsection{Usuário aluno}

Para um maior conhecimento do aluno deficiente visual, foram estudados o caso de oito alunos da rede pública regular da cidade de Canoas, sendo que, cinco eram totalmente cegos e três com baixa visão. 
Os alunos foram avaliados por meio de um questionário com perguntas pertinentes ao assunto da geografia e, através de uma oficina de percepção, onde puderam interagir com alguns elementos naturais, como: folhas, cascas de arvores, pedras e etc. como mostra a figura 3 a seguir.

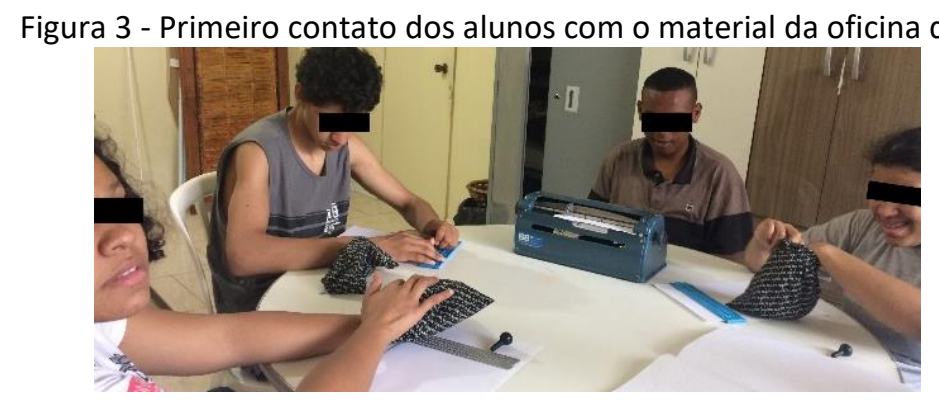

Fonte: Elaborada pela autora, 2017.

\subsection{Usuário Educador da Sala de Recursos}

Para aprofundar o conhecimento com esse usuário foi realizada uma entrevista para três educadores da sala de recursos, sendo que desses, um possui cegueira total e, os outros dois, videntes. As entrevistas ocorreram individualmente, com o intuito de esclarecer dúvidas sobre a formação do orientador, como os mesmos auxiliam no aprendizado dos alunos deficientes visuais e principalmente suas maiores dificuldades de ensino.

\subsection{Usuário professor de geografia}

Para uma imersão total no usuário "professor de geografia", elaboraram-se dois itens de pesquisa. O primeiro item é uma pesquisa observatória de como são as aulas dos dois professores selecionados. Nessas aulas, as perguntas a serem respondidas durante a observação foram: como os professores explicam o conteúdo no quadro? Quais são os materiais disponibilizados para o aluno deficiente visual?

No segundo item, aplicou-se um questionário, no qual os professores responderam questões tais como: No conteúdo de relevo terrestre, os alunos deficientes visuais sentem dificuldade em quê? Quando o aluno tem cegueira, o que você faz para que o mesmo entenda o conteúdo adequadamente?

Dessa forma, observou-se a grande dificuldade do professor de Geografia em facilitar a compreensão do aluno. Os dois professores também tiveram muita carência no que diz respeito ao material que os alunos deficientes visuais necessitam, sendo que a falta de material adaptado também impede que o professor aprofunde o conteúdo para que o mesmo seja compreendido de forma facilitada pelo aluno.

\subsection{Viagem dos usuários}

A viagem do usuário é uma descrição passo-a-passo da interação de um usuário com um material ou produto. Ela também descreve o que o usuário faz imediatamente antes e depois de ter essa experiência, pois isso fornece algum contexto de uso. Uma jornada de usuário ajuda a entender a experiência que o mesmo já possui e garante que a lista de necessidades esteja completa. As viagens dos usuários alunos foram de extrema importância para a captação das necessidades e particularidades do projeto.

\subsection{Lista de necessidades capturadas de cada usuário}


De acordo com a Engineering Design Centre (2017), a captura das necessidades é o processo de identificação do que o "usuário" quer do projeto. De acordo com a tabela abaixo, é notório que as necessidades podem variar de um usuário para o outro, mas a alternativa a ser gerada tem o objetivo de assessorar a todos os usuários simultaneamente.

Tabela 1 - Necessidades capturadas

\begin{tabular}{|c|l|l|}
\hline \multirow{4}{*}{$\begin{array}{c}\text { Aluno } \\
\text { Deficiente } \\
\text { Visual }\end{array}$} & Aula monótona & \multicolumn{1}{c|}{ O que fazer } \\
\cline { 2 - 3 } & Material adaptado somente é disponivel em provas & Desenvolver material que atraía o aluno \\
\cline { 2 - 3 } & Letra pequena no livro & Fontes maiores e adaptar o braille \\
\cline { 2 - 3 } & Possuir material lúdico & Desenvolver jogo ou maquete \\
\cline { 2 - 3 } & Material tátil: disponível apenas cola em alto relevo & Utilizar materiais diferentes \\
\cline { 2 - 3 } $\begin{array}{c}\text { Educador da } \\
\text { Sala de } \\
\text { Recursos }\end{array}$ & Pificuldade em compreender a matéria & Material com áudio-descrição \\
\cline { 2 - 3 } & Alunos dispersos em sala de recursos & Desenvolver material que envolva todos os usuários \\
\cline { 2 - 3 } & Diminuir a frequencia das faltas dos alunos & Tornar a aula atrativa \\
\hline \multirow{3}{*}{$\begin{array}{c}\text { Professor(a) } \\
\text { de Geografia }\end{array}$} & Dificuldade em mostrar relevos & Otimizar o tempo em sala de aulda de modo criativo \\
\cline { 2 - 3 } & Falling aos alunos deficientes visuais & Desenvolver material tátil \\
\cline { 2 - 3 } & Pouco material adequado aos alunos deficientes visuais & Desenvolver material que estimule o aluno e auxilie o professor \\
\hline
\end{tabular}

Fonte: Elaborada pela autora, 2017.

\section{Criação}

Na fase da criação foi utilizado todos os dados específicos das pesquisas, de modo que, oferecesse ao projeto final características essenciais para um produto adequado ao aluno deficiente visual.

Nessa fase, as ideias foram estimuladas através de moodboard com alguns materiais existentes no auxílio da educação de geografia, brainstorming com as ideias contribuídas pelos alunos e mapa mental. Ferramentas utilizadas no design para obter um maior número de alternativas capazes de conceituar o produto.

Levando em consideração o conteúdo de Geografia a ser abordado em sala de aula (relevos) e a interatividade entre os alunos, a alternativa que mais se adequou foi a construção de um jogo lúdico, formado a partir da montagem no estilo quebra cabeça, onde suas peças juntas formam a imagem dos principais tipos de relevos.

\subsection{Protótipos}

O protótipo do quebra-cabeça iniciou com a escolha da imagem que o mesmo ia apresentar após a sua montagem, através do tema relevos do conteúdo de geografia do sexto ano. Em um primeiro momento, a imagem final iria ser dividida em apenas cinco partes/peças: planaltos, depressões, montanhas, planícies e mar. Para gerar maior interatividade entre os alunos, cada relevo foi subdividido em quatro partes, totalizando vinte peças do quebra-cabeça. Para um melhor manejo do usuário deficiente visual, foram desenvolvidas texturas diferentes para cada tipo de relevo, de modo que o aluno perceba, através do toque, a semelhança de cada peça pertencente ao relevo específico, como mostra a Figura 4. 
Um ponto primordial para a montagem do quebra-cabeça foi o tipo de separação de cada peça. De modo que esse processo fosse desenvolvido com fluidez, as peças tiveram um corte mais ondulado, tornando cada peça única e com formato mais anatômico.

Figura 4 - Protótipos das peças do quebra cabeça

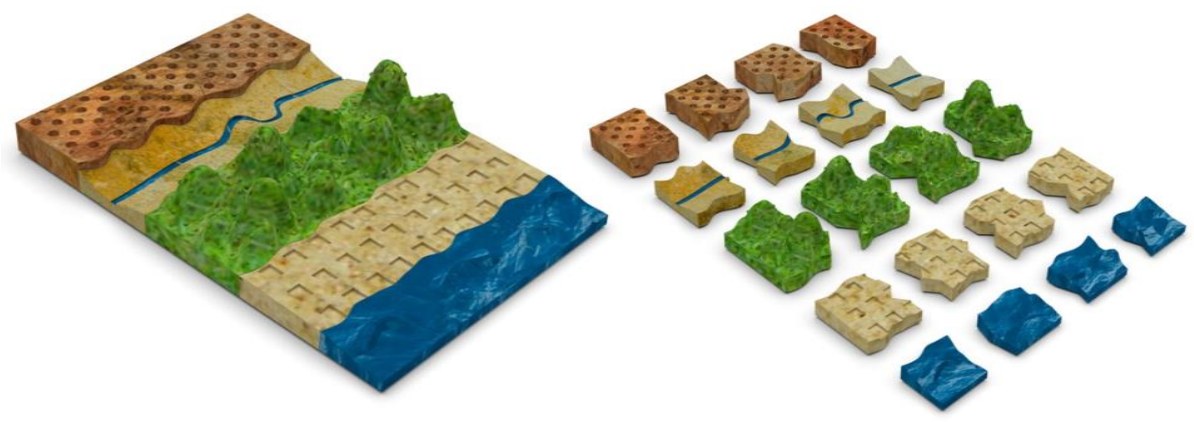

Fonte: Elaborada pela autora, 2017.

Com o objetivo de futura validação com os especialistas e usuários, o jogo de quebracabeça será impresso com o filamento em PLA (acrilonitrila butadieno estireno) $1.75 \mathrm{~mm}$, material este usado nas impressoras 3D, com resolução considerada: 0,2 $\mathrm{mm} /$ densidade de preenchimento: $20 \%$.

O desenvolvimento do protótipo de embalagem para o jogo quebra-cabeça foi de extrema importância, de modo que, um dos requisitos do projeto era que o produto fosse prático de ser armazenado.

Figura 5 - Protótipos do tabuleiro
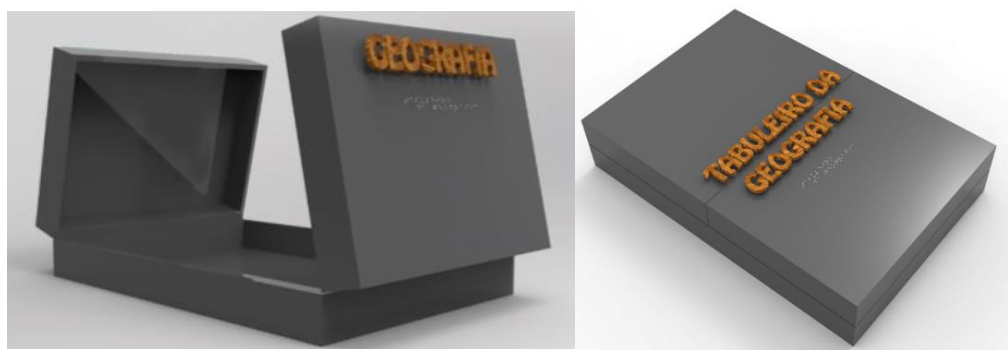

Fonte: Elaborada pela autora, 2017.

Conforme figura 5, as repartições laterais foram elaboradas para que a armazenagem das peças fosse feita. Nas duas divisões, foi colocado o tecido de rede, com o intuito de ter mais flexibilidade na hora em que o aluno deficiente visual fosse utilizar. Também se aplicaram ímãs nas extremidades dos compartimentos para um melhor fechamento do tabuleiro. A repartição do meio do tabuleiro irá servir para acomodar as peças no momento da montagem do quebracabeça.

A fabricação do tabuleiro foi realizada através da cartonagem, utilizando para a parte externa o papel Horle com espessura de três milímetros, revestido internamente e externamente com papel Color Plus na cor Dubai e gramatura de $120 \mathrm{~g}$.

Na finalização do tabuleiro, observou-se a necessidade da elaboração de um naming para o jogo. Como os principais usuários do tabuleiro são crianças deficientes visuais do sexto ano, onde o contato com uma língua estrangeira pode não ser tão familiar, optou-se em elaborar um nome 
na língua portuguesa. Sendo assim, foi aplicada a técnica de brainstorming onde o nome escolhido foi: Tabuleiro da Geografia.

Outro fator importante abordado foi a impressão desse naming em 3D, de modo que o mesmo fosse colocado na parte exterior da caixa, onde os usuários pudessem ter o primeiro contato tátil com o jogo. Após definido o nome do jogo, foi dado início ao desenvolvimento do manual do usuário. Para contemplar mais satisfatoriamente cada usuário, foram elaborados dois tipos de manual. Ambos possuem informações básicas sobre o jogo quebra-cabeça, as variações ocorrem apenas no modo de leitura. Para o manual dos deficientes visuais cegos, será impresso a escrita em braille. Já o manual para crianças videntes ou com baixa visão, foi elaborado com uma alta variação de contraste, proporcionando assim uma leitura e entendimento facilitado.

\section{Avaliação}

Após a fabricação do protótipo final do Tabuleiro da Geografia, o mesmo foi testado pelos usuários da pesquisa, alunos deficientes visuais, educadores das salas de recurso e professores de geografia, além de designers e outros profissionais da educação.

Para a avaliação foi aplicado um questionário onde, observou-se que o item que mais agradou os especialistas foram as texturas diferenciadas de cada relevo, reforçando assim a efetividade do produto. Outros pontos focais do Tabuleiro foram a abertura, pega das peças, conteúdo abordado, interatividade e função das texturas, sendo que todos obtiveram um resultado muito satisfatório.

$\mathrm{Na}$ ficha de avaliação e observação dos alunos, foi possível constatar a satisfação dos mesmos em relação ao jogo Tabuleiro da Geografia. Desde a abertura do tabuleiro, passando pela identificação de cada tipo de relevo e a montagem das peças. Percebeu-se a fluidez com que as ações ocorreram durante a experimentação, de modo que os alunos quiseram repetir por algumas vezes a montagem do jogo.

\section{Conclusão}

O presente estudo procurou trazer uma reflexão bastante significativa, que é a importância da inserção de temas que zelam pela inclusão no processo de aprendizagem. E, mesmo se tratando de um projeto com olhar bastante dirigido aos deficientes visuais, além de criar conhecimento acerca das particularidades relacionadas a esta deficiência, também permitiu obter consciência da importância de projetos que visam de fato ser universais.

Observou-se que através de conhecimentos e técnicas de design os espaços de ensinoaprendizagem poderiam ser muito mais desenvolvidos e ao mesmo tempo propiciaria as escolas maior inclusão e melhorias no aprendizado escolar. O aprofundamento do artigo/projeto, fez se perceber que essa área ainda é muito carente e necessita de muita adequação em relação a inclusão, seja através de materiais didáticos, móveis, conteúdos multissensoriais ou até mesmo em aprimoramentos de ensino dos próprios educadores.

Dessa forma, buscando a utilização dessas ferramentas do design, a metodologia seguida foi de extrema importância para o desenvolvimento do protótipo, pois possibilitou total interação com os alunos deficientes visuais, professores e educadores das salas de recursos juntamente com o auxílio das oficinas realizadas diretamente com os mesmos, foi possível desenvolver um produto que realmente atendesse as particularidades desse público. 
Com essa inserção, observou-se que cada criança dispõe da sua própria história, característica ou capacidade interior de se desenvolver, o que muitas vezes cria uma ilha à sua volta. Porém, brincar permitiu que elas interagissem de forma agradável e produtiva para o desenvolvimento das suas potencialidades. Dessa forma, o jogo Tabuleiro da Geografia, além de ser criativo, auxiliou para um melhor entendimento do conteúdo relevos.

O resultado final obtido atendeu os seus objetivos de maneira satisfatória. Porém, sua aplicação prática demanda mais estudos junto aos envolvidos. Por ser um protótipo e possuir uma linguagem facilitada para a montagem, este projeto também se tornou apto a ser aplicado não somente no conteúdo relevos, mas em diversos outros assuntos que possuam propostas similares e que o design possa auxiliar com a sua contribuição.

\section{Referências}

BARACHINI, Teresinha. Design de superfície: uma experiência tridimensional. In: Congresso Brasileiro de Pesquisa e Desenvolvimento em Design, 5., Congresso Internacional de Pesquisa em Design, 1., 2002, Brasília. Anais do P\&D Design, Brasília: [s.n.], 2002.

BINS ELY, Vera Helena Moro. Acessibilidade Espacial - Condição Necessária para o Projeto de Ambientes Inclusivos. In: MORAES, Anamaria de. (org). Ergodesign do Ambiente Construido e Habitado: ambiente urbano, ambiente publico, ambiente laboral. Rio de Janeiro: iUsEr, 2004.

BRASIL. Subsecretaria Nacional de Promoção dos Direitos da Pessoa com Deficiência. Comitê de Ajudas Técnicas. Tecnologia Assistiva. Brasília: CORDE, 2009. Disponível em: < http://www.pessoacomdeficiencia.gov.br/app/sites/default/files/publicacoes/livro-tecnologiaassistiva.pdf>. Acesso em: 07 mai. 2017.

BRUMINI, Cesar Dellore. Geografia - Coleção Projeto Araribá Plus - 6o Ano. São Paulo, SP. Editora Moderna, 2017.

CONDE, Guilherme C. Arquitetura para todos. In: Curso Básico sobre Acessibilidade ao Meio Físico e VI Seminário sobre Acessibilidade ao Meio Físico. Anais do... Brasília: Corde, 1994.

COSTA, Renata. Como Funciona o Sistema Braille. 2009. Disponível em: < http://novaescola.org.br/conteudo/397/como-funciona-sistema-braille>. Acesso em: 28 mai. 2017).

DIAS, Elizabet de Sá; CAMPOS, Izilda Maria de; CAMPOLINA, Myriam Beatriz Silva. Atendimento

Educacional Especializado em Deficiência Visual. Brasília, DF, 2007. Disponível em: <http://portal.mec.gov.br/seesp/arquivos/pdf/aee_dv.pdf>. Acesso em: 10 mai. 2017.

DISCHINGER, Marta; MATTOS, Melissa. Habitação Universal. Disponível em <http://www.ctc.ufsc.br/habuniversal>. Acesso em 06 jan. 2004.

ENGINEERING DESIGN CENTRE. Inclusive Design Toolkit. University of Cambridge. Reino Unido: 2017. Disponível em: < http://www.inclusivedesigntoolkit.com>. Acesso em: 19 nov. 2017.

FALCATO, Jorge Simões; BISPO, Renato. Design Inclusivo Acessibilidade e Usabilidade em Produtos, Serviços e Ambientes. Lisboa, Portugal, 2006.

FETTERMANN, Beatriz Feitosa. O Design De Superfície Como Mediador Da Relação Sujeito- 
Objeto. 2016. Disponível em: <http://repositorio.uniceub.br/bitstream/235/9584/1/21309388.pdf >. Acesso em: 28 mai. 2017.

ISOTANI, S.; MIZOGUCHI, R., BITTENCOURT, I. I., COSTA, E. (2008). Web 3.0: Os Rumos Da Web Semântica E Da Web 2.0 Nos Ambientes Educacionais. In Actas do XIX Simpósio Brasileiro de Informática na Educação. Disponível em: <http://br-

ie.org/pub/index.php/sbie/article/view/767/753>. Acesso em: 10 mai. 2017.

LIRA, Eder, et. al. $O$ que vê quem não vê? (Um estudo com aprendizagens geográficas de alunos com deficiências visuais). 2010. Disponível em: <https://pt.slideshare.net/dmd3284/o-queve?from_action=save $>$. Acesso em: 19 mai. 2017.

MEC. Ministério da Educação e Cultura. Brasil. Secretaria de Educação a Distância. Deficiência Visual. Brasília, DF, 2000. Disponível em:

<http://www.dominiopublico.gov.br/download/texto/me000344.pdf>. Acesso em: 07 mai. 2017.

PINTO, Marcelo Guimarães. Uma Abordagem Holística na Prática do Design Universal. In CORREA, Rosa Maria, org; Avanços e desafios na construção de uma sociedade inclusiva, Belo Horizonte : Sociedade Inclusiva/PUC-MG, 2008.

REINEHER, D. R. Um estudo sobre certos recursos facilitadores para o ensino da matemática aos alunos com deficiência visual. Monografia, Licenciatura em Matemática, Unioeste, Cascavel, 2008. Disponível em: <http://www2.td.utfpr.edu.br/semat/I_semat/AS.pdf>. Acesso em: 09 mai. 2017.

RUTHSCHILLING, Evelise Anicet. Design de superfície. Porto Alegre, RS: Editora da UFRGS, 2008.

SÃO PAULO. Acessibilidade Mobilidade Acessível na Cidade de São Paulo publicação da secretaria municipal da pessoa com deficiência e mobilidade reduzida (smped) - Prefeitura de São Paulo Secretaria Municipal da Pessoa com Deficiência. São Paulo. 2011.

SANTOS, Fabiana. A Inclusão dos Deficientes Visuais na Escola Regular. 2015. Disponível em: <http://www.deficienciavisual.pt/txt-inclusao_DV_escola_regular.htm>. Acesso em: 28 mai. 2017.

SCHÄFFER, Neiva O. et al. Um globo em suas mãos: práticas para a sala de aula. Porto Alegre: Editora da UFRGS/Núcleo de integração Universidade \& Escola da PROREXT/UFRGS, 2003. p. 158.

SILVA, Suzana Silrene; CARNEIRO, Relma Urel Carbone. Inclusão Escolar De Alunos Público-Alvo Da Educação Especial: Como Se Dá O Trabalho Pedagógico Do Professor No Ensino Fundamental?. Disponível em:

<http://seer.fclar.unesp.br/iberoamericana/article/view/8935/5877>. Acesso em: 07 mai. 2017.

SPERB, Cindi. Projeto De Comunicação E Sinalização Para Pessoas Com Deficiência Visual Baseado Em Percepções Tateis. Disponível em:

<http://biblioteca.feevale.br/Monografia/MonografiaCindiSpers.pdf>. Acesso em: 07 mai. 2017.

VITAL, Flavia Maria de Paiva; RESENDE, Ana Paula Crosara. A Convenção sobre Direitos das Pessoas com Deficiência Comentada. Brasília: Secretaria Especial dos Direitos Humanos. Coordenadoria Nacional para Integração da Pessoa Portadora de Deficiência, 2008. Disponível em <http://www.tvjustica.jus.br/documentos/Convencao\%20Comentada.pdf>. Acesso em: 07 out. 2014. 